\title{
Healthcare Facilities Management in Digitalization Context
}

\author{
(CrossMark \\ Veresniuk Nataliia a, Anastasiia Barzylovych ${ }^{b}$, Alina Zabolotna ${ }^{c}$, Mariia Boiko d, Ivan Rybchych ${ }^{\mathrm{e}}$ \\ Manuscript submitted: 27 June 2021, Manuscript revised: 18 September 2021, Accepted for publication: 09 October 2021
}

\section{Corresponding Author ${ }^{\text {a }}$}

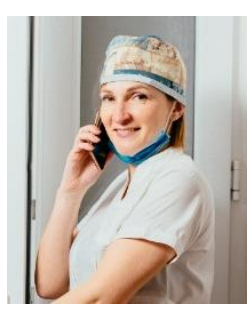

\section{Keywords}

healthcare digitalization; healthcare facilities; healthcare management; healthcare providers; healthcare services; healthcare system; medical institutions; pandemic environment;

\section{Abstract}

In 2020-2021, the digitalization of medical institutions and their management systems is one of them during the coronavirus pandemic. This research reveals that the healthcare system crisis due to the spread of the pandemic not only revealed weaknesses but was an engine for accelerating technological change even in the face of limited financial resources. In Germany, Italy, and France the crisis provided: 1) the development of telemedicine and online tools (to assist departments of medical institutions and doctors, assess the health of patients, remotely provide recommendations for further action (doctor's appointment or testing), provide contact information for medical institutions), creating technologies for screening the spread of the virus in the country; 2) strengthening collaboration with international partner companies, non-profit organizations, and local healthcare departments to implement practical solutions to provide remote support based on telemedicine technologies needed by patients under the isolation; 3 ) the adoption of regulations for the development of digital infrastructure of hospitals to digitalize the organization of processes, documents, and communication. The pandemic spread was the impetus for the introduction of technological solutions in other areas of medicine to meet the healthcare needs of diabetology, cardiology, oncology, neurology, and psychology.

\section{Contents}

Abstract

1 Introduction...

2 Materials and Methods.

3 Results and Discussions

a Danylo Halytsky Lviv National Medical University, Lviv, Ukraine

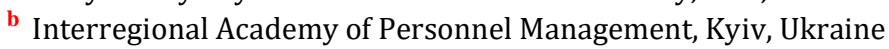

c Kyiv Medical University, Kyiv, Ukraine

d Vasyl Stefanyk Precarpathian National University, Ivano-Frankivsk, Ukraine

e Ivan Bobersky Lviv State University of Physical Culture, Lviv, Ukraine 
Acknowledgments..

References

438

Biography of Authors .

440

\section{Introduction}

There are always weaknesses in the management of healthcare facilities, which during a crisis lead to the inability of the healthcare system to cope with challenges and threats, the need for rapid management decisions to overcome threats. One such weakness in 2020-2021 is the digitalization of healthcare facilities and their management system in the spread of the coronavirus pandemic. The level of digitalization has been insufficient, even in developed countries, to effectively accompany, support, and advise the population, resulting in the need for instant management response to the problem. For example, in Germany, a new online telemedicine tool was introduced in 2020 to assess the symptoms of the coronavirus (the "Act on the Future of Hospitals") was adopted to develop digital infrastructure to optimize communication processes, paperwork, and telemedicine. In Italy, government action has intensified to integrate digitally practical solutions to provide patients with remote healthcare services (support, health monitoring for preventive purposes, etc.). In France, because of the corona crisis, a monitoring platform has been launched to track the condition of patients with COVID-19, telephone support lines for the population have been created (Barzylovych et al., 2020). The above examples confirm the digital unpreparedness of medical institutions for the crisis actualizes the problem of studying the management of medical institutions under the conditions of digitalization (Miyazaki \& Une, 2005). This article aims to systematize the peculiarities of medical institution's management in the context of digitalization on the example of healthcare systems of Germany, Italy, and France during the coronavirus.

\section{Materials and Methods}

The scientific literature discusses the managerial challenges of digitization of healthcare facilities, digitalization strategies for healthcare facilities, and digitization roadmaps with a focus on hospital facilities as a key element of the healthcare system, the benefits of digitization and the structure of healthcare digitization, the challenges, and potential of digitization (Gjellebæk et al., 2020; Zhao \& Canales, 2021; Beaulieu \& Bentahar, 2021; Odone et al., 2019). Glauner et al. (2021), examine aspects of the use of artificial intelligence, healthcare programs, experimental approaches to digitalization, opportunities, risks of digitalization, and the potential to solve healthcare facility problems through IT solutions. Lapão (2019), highlights the challenges of healthcare digitization, the implementation of digital services, and the impact of digitization on the performance of healthcare professionals. Digitalization of healthcare will change the paradigm of healthcare delivery, mechanisms of patient participation and engagement, and determine the sustainability of healthcare facilities depending on the design of digital services. As Kokshagina (2021) notes, digital technologies of health services delivery provide value creation in healthcare.

Scientific publications note the low level of digitalization of healthcare facilities and the high potential for technology adoption at various levels of management (Gjellebæk et al., 2020; Beaulieu \& Bentahar, 2021). Among the main reasons for low technology penetration in eHealth is knowledge in the context of the need to develop technology skills and benefits (Zhao \& Canales, 2021), staff training, and the need for stakeholder collaboration in integration (Gjellebæk et al., 2020). Collaboration involves the need to involve staff, patients in creating, developing digital solutions to understand users (their problems, needs, perceptions, etc.), also require significant amounts of funding and time for staff, patient testing of technology (Garmann-Johnsen et al., 2020). Additional reasons are lack of funding since infrastructure, and diagnostic technologies require significant amounts of long-term investment (Moro Visconti \& Morea, 2020). It is possible to solve these problems through a middle management strategy, which is crucial in the transformation of healthcare services (Gjellebæk et al., 2020). It is the middle management level that should be responsible for engaging 
and motivating workers in the process of technology co-creation, horizontal and vertical use (GarmannJohnsen et al., 2020; Susilo et al., 2021).

The development of eHealth involves new and innovative work processes, and employees and managers must be aware of a dramatic change in the workplace, a shift from routine processes to continuous staff learning, digital skills development, and stakeholder technology practices (Gjellebæk et al., 2020). For example, thanks to digital platforms, communication processes, knowledge sharing among staff, and workflow (a technological business model that facilitates exchanges between interacting agents) are dramatically changing (Moro Visconti \& Morea, 2020). Odone et al. (2019), point to the following main benefits of digitalization of healthcare "(i) Personalization and precision; (ii) Automation; (iii) Prediction; (iv) Data analytics and (v) Interaction". In this case, digital platforms as a component of digitization and eHealth are a point solution. They are patient-centered primarily to improve the interaction between medical staff and healthcare recipients, communication within healthcare facilities.

To analyze the management of healthcare facilities in the context of digitalization, the most developed countries in terms of telemedicine were chosen: Germany, Italy, and France. Using the example of healthcare system management under conditions of coronavirus, the main components of the digital management subsystem at the national (systems of situation monitoring, psychological support of the population, patient health assessment) and local levels (organization of medical services using technology by healthcare facilities, communication, information and data exchange, document management) were identified.

This research used the World Health Organization database, which contains Health Systems Response Monitoring (HSRM), to collect and systematize information on countries' policies in response to the pandemic. https://www.covid19healthsystem.org/searchandcompare.aspx. We compare data from Germany, Italy, and France according to the following criteria:

1) Strategic management.

2) Effective healthcare system service provision: 2.1) care planning; 2.2) case management.

3) Healthcare system financing.

\section{Strategic management}

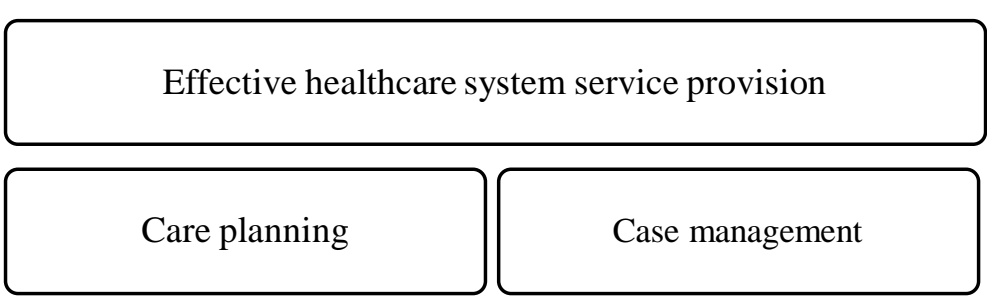

Healthcare system financing

Figure 1. The components of a healthcare management digital system

Source: author's note

To assess the level of financial support for the countries' healthcare management systems, the OECD data on expenditures and healthcare system financing in Germany, France, and Italy in 2010-2019 for the function "Governance and healthcare system and financing administration" were used. The main limitation of this research is the lack of information on particular components of the digital healthcare facilities management system. For example, the lack of data on the strategic management of medical institutions in Germany and France due to digital technology can only mean the actual low digitalization of this component.

Nataliia, V., Barzylovych, A., Zabolotna, A., Boiko, M., \& Rybchych, I. (2021). Healthcare facilities management in digitalization context. International Journal of Health Sciences, 5(3), 429-440. https://doi.org/10.53730/ijhs.v5n3.1773 


\section{Results and Discussions}

\section{Germany: effective provision of healthcare system services}

During the pandemic, Germany saw an increase in the number of teleconsultations and video consultations by general practitioners and psychotherapists. The government lifted some kinds of restrictions on the field of telemedicine, particularly regarding the number of consultations that can be provided via video or audio linkage. In Germany, a virtual hospital has been launched, assisting other departments and practitioners. The Charité University Hospital has launched the "CovApp" (https://covapp.charite.de/), an online resource for assessing patients' health status, providing recommendations on further action (making an appointment with a doctor or undergoing testing) and providing contact information for medical institutions, hospitals, or centers where examinations can be performed.

From April 21, 2021, a new online telemedicine tool is available in Germany to help patients assess their symptoms and address questions related to COVID-19. The Central Research Institute for Ambulatory Health Care in Germany (Zi), together with international partner companies from Switzerland and Italy, has developed the COVID Guide (https://covidguide.health/de/). The Guide allows people to get an initial assessment of their condition. Users can enter their symptoms and use the handbook to distinguish between signs of COVID-19, the flu, and the common cold. The Guide also contains important information from the WHO and government agencies.

It is worth noting that the costs of healthcare system funding for the management and financial administration of healthcare facilities in Germany, France, and Italy differ significantly between 2010 and 2019. France has the highest share of funding at $0.7 \%$ on average over ten years, while Italy has only $0.1 \%$ and Germany $0.55 \%$ on average over ten years. The low indicator of management costs caused the crisis in the management of facilities in Italy. It is worth examining in more detail the peculiarities of the financing of medical institutions of the countries and the management efficiency due to the financial resources that the network of institutions receives.

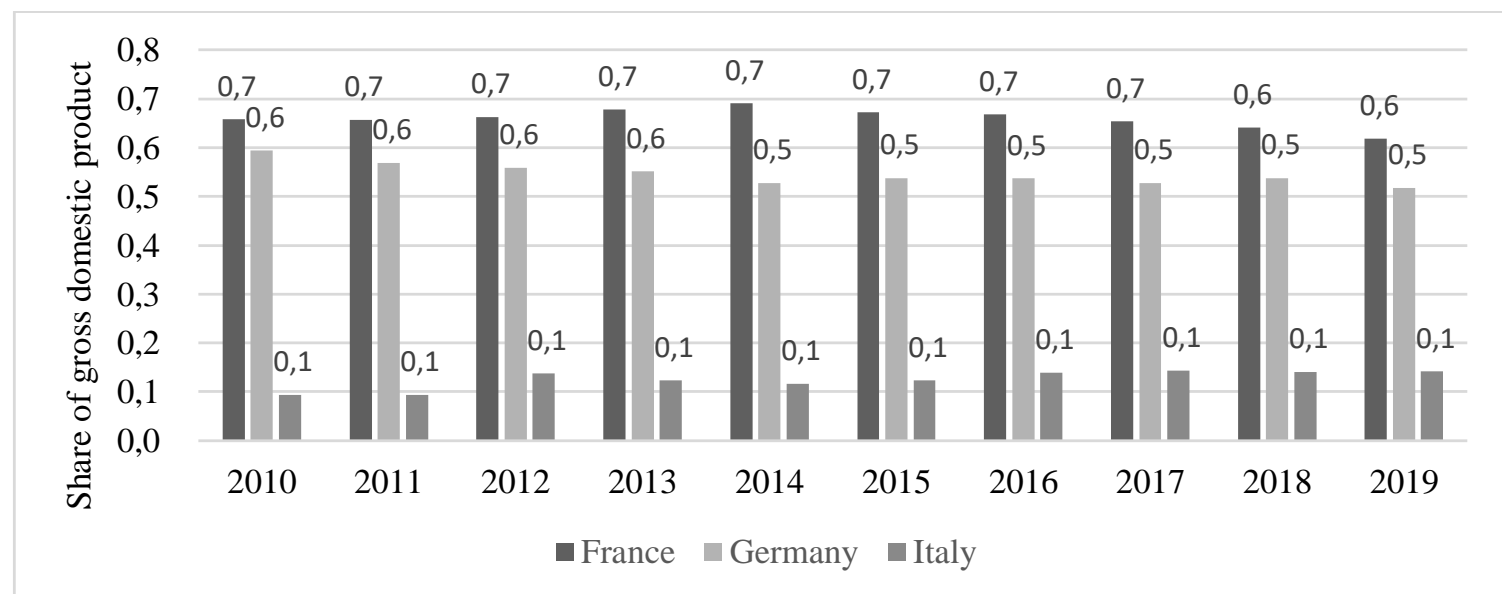

Figure 2. Healthcare system expenses and financing dynamics in Germany, France, and Italy during 20102019 according to "Governance and healthcare system and financing administration" function, \% of GDP Source: Health expenditure and financing. https://stats.oecd.org

Germany: the healthcare system' financing

In a pandemic environment, the digitalization of healthcare facility management is increasing in Germany. On September 2, 2020, the German government approved the "Future of Hospitals Act", which is designed to develop the digital infrastructure of hospitals over the coming years. Approximately 4 billion euros have been allocated for this, of which 3 billion euros will come from the government budget and another 1,3 billion will come from federal municipalities. 
The coronavirus pandemic has intensified the problems associated with insufficient or rapid implementation of digitalization and networking programs for hospitals, partly due to a lack of capital investment from municipalities (Megahed \& Ghoneim, 2020; Barra Novoa et al., 2021). The new Future of Hospitals Act will provide investments in emergency care and digital infrastructure to strengthen systems of care at the institutional, internal sector, and cross-sector levels - in particular digitalization of areas of work such as process management, document management and communication, and the introduction or enhancement of telemedicine, robotics and high-tech medicine. Financial resources will also be allocated, for information security and the development of regional service structures, to harmonize delivery systems and ensure their effective operation both in normal times and in crises. The new funding fund for the digitalization of medical institutions will also enable the expansion of staffing and the implementation of cross-border projects (Mamontova et al., 2021). The effectiveness of efforts to digitize the healthcare system will be evaluated between 2021 and 2023. The fund, which is being established within the Federal Social Security Administration, is funded by the federal government, the federal states, and the funding agencies starting in January 2021. The federal states can apply for funding now.

\section{Italy: strategic management}

Italy's COVID-19 strategic guidance for the healthcare system encompassed action plans for managing the healthcare system to ensure its continuity of operations. The management included emergency response mechanisms: dissemination of information, regulation of services for patients affected by the virus (Ningsih et al., 2021; Novoa, 2021).

On April 14, 2020, the Italian government released the report "Provisional Guidelines for Telemedicine Services during the COVID-19 Pandemic," which presents the national guidelines for telemedicine. Since the beginning of the pandemic, the National Center for Telemedicine and New Assistive Technologies at the National Institute of Health has collaborated with local healthcare departments in Italy to implement practical solutions to provide remote support based on telemedicine technologies needed by patients in isolation. Technology solutions are implemented to track health conditions in the context of COVID-19 prevention and treatment, provide care and respond to other medical problems (Popova et al., 2020).

During a parliamentary hearing on June 10, 2020, the Minister of Health noted the need to invest in artificial intelligence and digitalization to connect research institutes and local healthcare facilities with other centers in Italy and other countries. A study by the Observatory for Digital Health Innovation found that citizens use at least one online platform for services and appreciate the functionality of the electronic health prescription system introduced during the COVID-19 pandemic (Asman et al., 2021; Widana et al., 2021). On March 31, 2020, the Ministry of Technology Innovation and Digitalization established an expert group with task subgroups to work on the following areas:

1) General coordination of activities.

2) Digital infrastructure and data collection.

3) The economic impact of digitalization on healthcare facilities.

4) Web data and socioeconomic impact.

5) Telemedicine.

6) Emergency management technologies.

7) Big data and artificial intelligence for policymaking.

8) Legal profiles of data management during an emergency, in particular, subgroups evaluated proposals and technology solutions sent to participate in the "Express Contest for Technology Proposals to Contain COVID-19," a joint effort of the Department of Economic Development, Department of Education, Universities, and Research and Department of Health from March 24 to 26.

The competition was held to select the best applications and solutions for providing remote support at home to patients - both those with COVID-19 and those with other conditions, including chronic conditions. Functional applications already available on the market were accepted for the competition. Priority was given to solutions that provide active monitoring of patients on self-isolation for home care. Five apps were selected from 504 submissions. Applications were evaluated based on criteria such as technical characteristics,

Nataliia, V., Barzylovych, A., Zabolotna, A., Boiko, M., \& Rybchych, I. (2021). Healthcare facilities management in digitalization context. International Journal of Health Sciences, 5(3), 429-440. https://doi.org/10.53730/ijhs.v5n3.1773 
methodology for patient/citizen identification and verification, and project timelines. As a result, the following apps were selected: LazioDrCovid, Co4Covid-19, Smart Axistance Covid-19 Control, Ticuro Reply, and lifecare Covid-19. In Italy, the focus is on mapping the spread of the virus in the country through nationwide screening and the use of high technology to track cases. The program not only tracks the movement of infected people and identifies contacts but also provides the population with access to basic telemedicine and digital healthcare services.

\section{Italy: effective provision of healthcare system services}

From March 1 to May 8, 2020, Italy implemented a total of 108 initiatives (digital solutions) to improve service delivery through digital technologies, with the number rising to 149 (by May 26) and 174 (by June 11). At the same time, only 50 technological solutions of the total have been implemented to address the spread of COVID-19, others are dedicated to diabetology, cardiology, oncology, neurology, and psychology. The goal of the solutions is to address healthcare needs in areas that are not related to COVID-19. As of June 11, these services include phone calls ( 20 percent) or video calls ( 29 percent), with the ability to share documentation using email or instant messaging platforms. Some of these applications are specifically designed for teleconsultation and monitoring (13\%), and several Web-based platforms allow healthcare market operators to collaborate (38\%). The services most often provided by digital solutions include medical examinations (47\%), health monitoring to identify vital signs (33\%), and consultations (8\%). Developed applications include solutions for assisting nursing homes and communicating with family members. The above-mentioned web platforms are mostly used for patients with COVID-19 and cardiovascular diseases. Diabetics are usually assisted by telephone or video calls. Phone calls are often made by general practitioners, while oncologists and dermatologists use Web-based platforms.

In June 2020, Italy issued the "Directive on the gradual restoration of activities deferred during the COVID19 emergency," which recommends the use of remote patient support technologies (teleconsultations, telemedicine) wherever possible, in particular for examinations and adjustments of treatment plans. The facilities are encouraged to prioritize remote methods (for making appointments and managing payments by phone or online transactions). As of May 26, four Italian regions out of twenty (Emilia Romagna, Lombardy, Tuscany, and Veneto) and the autonomous province of Trento have issued regulations that allow the official creation of conditions for the provision of healthcare services through telemedicine. According to the ALTEMS report, as of September 3, the number of regions that have issued resolutions on the use of telemedicine tools in their healthcare systems has increased to 10, plus two autonomous provinces. Some regions have adopted general organizational plans, while others have adopted guidelines for specific diseases (e.g., Abruzzo for diabetes and autism) or categories of patients (e.g., Lazio for pediatric patients). Lombardy and Piedmont have adopted instructions on the list of remote services. Seven regions have developed tariff systems.

\section{Italy: the healthcare system' financing}

Italy's National Recovery and Resilience Plan were developed in April 2021 as a prerequisite for receiving funds from the EU Recovery Fund. Among the activities to be financed in the healthcare sector, investments in digitalization, electronic healthcare records, and telemedicine are foreseen.

To overcome the coronavirus-related emergency, Italy's National Health Service has received additional funds. There are two main channels of additional funding: 1) Public funding through a decree of March 17, 2020 (according to the decree, the National Health Service and the Department of Civil Defense receive 3.2 billion euros of the total 25 billion euros allocated by the government to combat emergencies 2) Donations from individuals and large companies that assist regions, municipalities and healthcare providers (as of March 29,2020 , the total amount of donations was 425.6 million euros).

Donations are collected through online crowdfunding platforms, on which individuals, non-profits, and other philanthropists conduct numerous fundraising campaigns. An example is the innovative nonprofit startup Italia, which has developed a platform on which hospitals submit fundraising requests. At the same time, the startup monitors all other charitable initiatives implemented by companies, foundations, and individuals to help those in need in emergencies. In Italy, 309 such initiatives have already been registered during 2020, and donations amount to 425.6 million euros. Beneficiaries can dispose of donations at their 
discretion (based on a rapid need assessment) unless donors have specified the purpose of the allocation. All expenditures are accounted for in special balance sheet accounts called COVID-19, and for the sake of accountability and transparency, information about each transaction made must be made publicly available. Funds are mainly used to improve the material and technical equipment of medical institutions through the placement of new beds and the purchase of necessary equipment. Special attention is paid to the purchase of protective equipment for medical and non-medical staff. As of April 16, 2020, Italian citizens have donated 125 million euros to the Department of Civil Defense to purchase equipment for hospitals. A private philanthropist started a fund to support the families of medical professionals who died while assisting patients with COVID-19.

\section{France: effective provision of healthcare system services}

In France, a small number of initiatives have been implemented to provide home monitoring for high-risk patients and at the same time relieve emergency services. The university hospital foundation Assistance Publique - Hôpitaux de Paris (APHP), which operate in Paris and surrounding areas, launched a telemonitoring platform from March 9, 2020, that allows the daily automated follow-up of patients who test positive for coronavirus or are suspected to have contact with someone with COVID-19, but without severe symptoms. The platform, which served about 30,000 patients as of March 31, 2020, is supported by about 200 to 300 trained medical professionals and supported by volunteer physicians who call 4,000 to 6,000 people daily, depending on the alarms received. The goal is to keep patients from making an unnecessary trip to the hospital on their own, but at the same time, to convince patients to go to the hospital immediately if they notice their condition worsening.

Telephone hotlines have been set up to assist mental health services as a result of the outbreak, targeting the general population. The hotlines support teleconsultations with mental healthcare professionals. Many psychiatrists warn that in addition to actions targeting the general population, during the COVID-19 epidemic, people with already diagnosed mental disorders should not be forgotten as an extremely vulnerable population.

\section{France: the healthcare system financing (services' fee)}

The National Health Insurance Fund has simplified the provision and reimbursement of teleconsultations, which have the benefit of limiting the risk of infection. On March 18, 2020, it was announced that $100 \%$ of the cost of teleconsultations will be covered during this period (at least through April 30) to avoid out-of-pocket costs for the patient. In addition, Doctolib, the largest online doctor appointment, and consultation company has decided to provide its services and platform for free, providing access to 80,000 doctors during the quarantine period. At the start of the pandemic, only 3,500 doctors were signed up for the service. Doctors are allowed to use this consultation format without the need-to-know patient information and follow the usual routing recommendations, which were previously impossible. At the same time, this option was made available to nurses to monitor patients infected with the COVID-19 virus who are being treated at home. By mid-April, teleconsultations were available to midwives, speech therapists, occupational therapists, and psychotherapists, for all their patients without any restrictions. Physical therapists were able to take advantage of the new digital consultation method on April 18, 2020. During the COVID-19 outbreak, the frequency of teleconsultations increased exponentially: about 40,000 teleconsultations were performed in just 1 day (March 23, week 13), which is about 10\% of all consultations. At the same time, this number of teleconsultations usually amounted to $1 \%$ of the total volume with reimbursable for the month. In addition, to meet the needs of people who do not have access to the Internet (often among the elderly population), the Ministry of Health announced on April 14 that telephone consultations during the COVID-19 epidemic will be reimbursed in the same way as regular consultations. This kind of counseling, however, is only available to COVID-19 symptomatic patients who are 70 years of age or older or who have a chronic medical condition and whose medical care is based on the presence of a long-term illness.

The lack of strategic management of the digitalization of medical institutions in Germany has led to increased problems of insufficient digitalization projects and programs in the country due to limited funding

Nataliia, V., Barzylovych, A., Zabolotna, A., Boiko, M., \& Rybchych, I. (2021). Healthcare facilities management in digitalization context. International Journal of Health Sciences, 5(3), 429-440. https://doi.org/10.53730/ijhs.v5n3.1773 
at the national and federal levels. The share of healthcare system funding for the management and financial administration of medical institutions in Germany was $0.55 \%$ of GDP on average over ten years. As a result, during the pandemic, a law was passed to develop the digital infrastructure of healthcare facilities. In times of crisis, the government is lifting restrictions on the volume of technology-enabled medical services. In addition, work is intensifying on the implementation of online tools for patient health monitoring and counseling. An assessment of the state of healthcare facilities' digitalization during the pandemic revealed inefficiencies in the management of Germany's healthcare system. Funding cuts, especially after the 2008 crisis, negatively affected hospitals during the crisis and put pressure on both management structures in the context of rapid decision-making about digitalization and staff in the context of the need to switch to digital tools for patient interaction.

In Italy, during the crisis, the government intensified the strategic management of healthcare facilities through national action plans and directives, increased collaboration with local healthcare departments, research institutes, and local healthcare facilities with other centers and other countries. The spread of the pandemic stimulated the government to intensify work on the coordination of facilities, digitalization of infrastructure, assessment of the economic effects of digitalization, collection of web data, development of telemedicine, implementation of artificial intelligence. The result was the selection of applications to provide remote home support to patients with various diseases other than coronavirus and the creation of a digital map of the spread of the virus. In Italy, a total of 108 digital solutions have been introduced to improve the efficiency of service delivery through digital technologies, particularly in diabetology, cardiology, oncology, neurology, and psychology. Several web-based platforms have enabled the collaboration of healthcare market operators.

Italy's main weakness in healthcare facilities management was the catastrophically low level of funding ( $0.1 \%$ of GDP over ten years). This necessitated the immediate mobilization of funds from the EU Recovery Fund to finance digitalization, electronic health records, and telemedicine. An additional source of funding has been online crowdfunding platforms, where hospitals leave requests to raise resources to improve the logistics of medical facilities through the placement of new beds and the purchase of necessary equipment.

It seems that unlike Germany and Italy, which significantly reduced funding for medical facilities through budgetary constraints after the 2008 crisis, in France, the large share of funding behind the management and administration function ensured less risk during the spread of the pandemic. Therefore, in France, the management of healthcare facilities during the pandemic involved only increased digital telemonitoring of patient monitoring and increased patient care through digital platforms. Additional measures were the simplification of reimbursement conditions for teleconsultations. In France, the crisis in the healthcare system contributed to the proliferation of private digital platforms to provide healthcare services to patients. As a result, there has been a rapid exponential development of telemedicine.

This research allows us to consider the healthcare crisis as an opportunity for transformation and an engine of digitalization despite budgetary constraints. Traditionally, the academic literature has viewed the healthcare crisis as a state of inability to effectively address the negative health effects on populations with certain types of diseases (Small et al., 2017; Saloner et al. 2018). Thus, this research proves that during the crisis, telemedicine services are expanded, financial resources are attracted, and collaboration is intensified to provide patients not only with coronavirus symptoms but also with other chronic diseases. The crisis was seen as ineffective management due to lack of funding and limited reform of the healthcare system, which is amplified by the influence of socio-economic factors (Economou et al., 2015). However, the study reveals how the government engages the private sector, non-profit organizations, the EU Funding Facility, and municipal budgets in times of crisis.

The literature also identifies that in a crisis, medical institutions cannot overcome the problems of diseases of different types due to different factors on their own. "In this time of crisis, innovative and adaptive methods of practicing will be required across all healthcare professions" (Cadogan \& Hughes, 2021). Factors that increase the crisis include primarily inadequate management of the healthcare system, particularly in the context of the disease's spread, lack of resources (human, logistical, financial, technological, informational, institutional (Jones, 2020; Solomon et al., 2020). However, this research confirms that the crisis triggered the activation of strategic management, approval, or updating of the plan to counteract the negative effects. The intensification of management has contributed to an increase in funding, as a consequence of increased digitization and logistics. Factors also include insufficient access to healthcare services for the population, 
ineffective public management, lack of strategies, social security mechanisms (Correia et al., 2015; Saloner et al., 2018). At the same time, it was digitalization that increased patients' access to healthcare services.

The strategies developed for the management of healthcare facilities at the national and municipal level (Hic et al., 2020), the integration of a strategic approach, the clear elaboration of crisis management plans to meet the needs of the population (Economou et al. 2015; Spinelli \& Pellino, 2020), have contributed to an effective mechanism for the management of healthcare facilities in crisis. Monitoring, screening, and innovation in times of crisis have become important elements of healthcare crisis response policies (Correia et al., 2015; Liu et al., 2020).

\section{Conclusion}

This research discovered that the healthcare system crisis due to the spread of the pandemic, not only revealed weaknesses but was the engine for accelerating technological change even in the face of limited financial resources. In Germany, Italy and France the crisis provided: 1) the development of telemedicine and online tools (to assist departments of medical institutions and doctors, assess the health of patients, remotely provide recommendations for further action (making appointments or getting tested), provide contact information of medical institutions), the creation of technologies for screening the spread of the virus in the country; 2) strengthening collaboration with international partner companies, with local healthcare departments to implement practical solutions to provide remote support based on telemedicine technologies needed by patients under isolation; 3) the adoption of regulations to develop the digital infrastructure of hospitals in order to digitize the organization of processes, work with documents and communication, the introduction or improvement of telemedicine, robotics and high-tech medicine, information security and the development of regional service structures in the healthcare field. The spread of the pandemic was the trigger for the implementation of technological solutions in other areas of medicine to meet the healthcare needs of diabetology, cardiology, oncology, neurology, and psychology.

Acknowledgments

We are grateful to two anonymous reviewers for their valuable comments on the earlier version of this paper.

Nataliia, V., Barzylovych, A., Zabolotna, A., Boiko, M., \& Rybchych, I. (2021). Healthcare facilities management in digitalization context. International Journal of Health Sciences, 5(3), 429-440. 


\section{References}

Asman, A., Asman, A., \& Dewi, A. K. (2021). Community nursing strategies for tourism health families during COVID-19 pandemic. International Journal of Health Sciences, 5(3), 224-231. https://doi.org/10.53730/ijhs.v5n3.1449

Barra Novoa, R., Limari, K., \& Limari, P. (2021). Current overview of assistance bioethics committees in Chile. International Journal of Health \& Medical Sciences, 4(1), 95-101.

Barzylovych, A., Oliinyk, Y., Kostitska, I., \& Buryk, N. S. Z. (2020). Transformation of the Social and Medical Spheres under the Conditions of COVID-19. Systematic Reviews in Pharmacy, 11(11), 1328-1337.

Beaulieu, M., \& Bentahar, O. (2021). Digitalization of the healthcare supply chain: A roadmap to generate benefits and effectively support healthcare delivery. Technological Forecasting and Social Change, 167, 120717. https://doi.org/10.1016/j.techfore.2021.120717

Cadogan, C. A., \& Hughes, C. M. (2021). On the frontline against COVID-19: Community pharmacists' contribution during a public health crisis. Research in Social and Administrative Pharmacy, 17(1), 20322035. https://doi.org/10.1016/j.sapharm.2020.03.015

Correia, T., Dussault, G., \& Pontes, C. (2015). The impact of the financial crisis on human resources for health policies in three southern-Europe countries. Health Policy, 119(12), 1600-1605. https://doi.org/10.1016/j.healthpol.2015.08.009

Economou, C., Kaitelidou, D., Kentikelenis, A., Maresso, A., \& Sissouras, A. (2015). The impact of the crisis on the health system and health in Greece. In Economic crisis, health systems and health in Europe: Country experience [Internet]. European Observatory on Health Systems and Policies.

Garmann-Johnsen, N. F., Helmersen, M., \& Eikebrokk, T. R. (2020). Employee-driven digitalization in healthcare: codesigning services that deliver. Health Policy and Technology, 9(2), 247-254. https://doi.org/10.1016/j.hlpt.2020.03.001

Gjellebæk, C., Svensson, A., Bjørkquist, C., Fladeby, N., \& Grundén, K. (2020). Management challenges for future digitalization of healthcare services. Futures, 124, 102636. https://doi.org/10.1016/j.futures.2020.102636

Glauner, P., Plugmann, P., \& Lerzynski, G. (2021). Digitalization in Healthcare: Implementing Innovation and Artificial Intelligence.

Hick, J. L., Hanfling, D., Wynia, M. K., \& Pavia, A. T. (2020). Duty to plan: health care, crisis standards of care, and novel coronavirus SARS-CoV-2. Nam Perspectives.

Jones, D. S. (2020). History in a crisis-lessons for Covid-19. New England Journal of Medicine, 382(18), 16811683.

Kokshagina, 0. (2021). Managing shifts to value-based healthcare and value digitalization as a multi-level dynamic capability development process. Technological Forecasting and Social Change, 172, 121072. https://doi.org/10.1016/j.techfore.2021.121072

Lapão, L. V. (2019). The future of healthcare: the impact of digitalization on healthcare services performance. In The Internet and Health in Brazil (pp. 435-449). Springer, Cham.

Liu, Q., Luo, D., Haase, J. E., Guo, Q., Wang, X. Q., Liu, S., ... \& Yang, B. X. (2020). The experiences of health-care providers during the COVID-19 crisis in China: a qualitative study. The Lancet Global Health, 8(6), e790e798. https://doi.org/10.1016/S2214-109X(20)30204-7

Mamontova, E., Buryk, Z., Strikha, L., Vonsovych, S., Voropayeva, T., \& Baranova, O. (2021). The Modern Experience of Lobbying Interests in Europe. Studies of Applied Economics, 39(8).

Megahed, N. A., \& Ghoneim, E. M. (2020). Antivirus-built environment: Lessons learned from Covid-19 pandemic. Sustainable cities and society, 61, 102350. https://doi.org/10.1016/j.scs.2020.102350

Miyazaki, M., \& Une, H. (2005). Infectious waste management in Japan: A revised regulation and a management process in medical institutions. Waste management, 25(6), 616-621. https://doi.org/10.1016/j.wasman.2005.01.003

Moro Visconti, R., \& Morea, D. (2020). Healthcare digitalization and pay-for-performance incentives in smart hospital project financing. International journal of environmental research and public health, 17(7), 2318.

Ningsih, S., Ismail, D., \& Indriani, I. (2021). Study protocol: relationship between parenting patterns and diet with nutritional status of toddlers during COVID-19 pandemic. International Journal of Health Sciences, 5(2), 128-134. https://doi.org/10.29332/ijhs.v5n2.1336

Novoa, R. B. (2021). State of the art and future applications of digital health in Chile. International Journal of Health \& Medical Sciences, 4(3), 355-361. 
Odone, A., Buttigieg, S., Ricciardi, W., Azzopardi-Muscat, N., \& Staines, A. (2019). Public health digitalization in Europe: EUPHA vision, action and role in digital public health. European journal of public health, 29(Supplement_3), 28-35.

Popova, T., Iskiv, M., Zagurska-Antoniuk, V., Buryk, Z., Matsyk, V., \& Terentieva, N. (2020). The Application of Public-Private Partnership for the Purpose of Implementing State Policy in the Sphere of Health Care. International Journal of Economics \& Business Administration (IJEBA), 8(3), 128-138.

Saloner, B., McGinty, E. E., Beletsky, L., Bluthenthal, R., Beyrer, C., Botticelli, M., \& Sherman, S. G. (2018). A public health strategy for the opioid crisis. Public Health Reports, 133(1_suppl), 24S-34S.

Small Jr, W., Bacon, M. A., Bajaj, A., Chuang, L. T., Fisher, B. J., Harkenrider, M. M., ... \& Gaffney, D. K. (2017). Cervical cancer: a global health crisis. Cancer, 123(13), 2404-2412.

Solomon, M. Z., Wynia, M. K., \& Gostin, L. O. (2020). Covid-19 crisis triage-optimizing health outcomes and disability rights. New England Journal of Medicine, 383(5), e27.

Spinelli, A., \& Pellino, G. (2020). COVID-19 pandemic: perspectives on an unfolding crisis. Journal of British Surgery, 107(7), 785-787.

Susilo, C. B., Jayanto, I., \& Kusumawaty, I. (2021). Understanding digital technology trends in healthcare and preventive strategy. International Journal of Health \& Medical Sciences, 4(3), 347-354.

Widana, I.K., Sumetri, N.W., Sutapa, I.K., Suryasa, W. (2021). Anthropometric measures for better cardiovascular and musculoskeletal health. Computer Applications in Engineering Education, 29(3), 550561. https://doi.org/10.1002/cae.22202

Zhao, Y., \& Canales, J. I. (2021). Never the twain shall meet? Knowledge strategies for digitalization in healthcare. Technological Forecasting and Social Change, 170, 120923. https://doi.org/10.1016/j.techfore.2021.120923

Nataliia, V., Barzylovych, A., Zabolotna, A., Boiko, M., \& Rybchych, I. (2021). Healthcare facilities management in digitalization context. International Journal of Health Sciences, 5(3), 429-440. https://doi.org/10.53730/ijhs.v5n3.1773 


\section{Biography of Authors}

\begin{tabular}{|c|c|}
\hline & $\begin{array}{l}\text { Veresniuk Nataliia } \\
\text { Ph.D., Associate Professor } \\
\text { Associate Professor of the Department of Obstetrics, Gynecology, and } \\
\text { Perinatology, Faculty of Postgraduate Education } \\
\text { Danylo Halytsky Lviv National Medical University } \\
\text { ORCID ID: https://orcid.org/0000-0001-5233-7105 } \\
\text { Email: veresniuk@ukr.net }\end{array}$ \\
\hline & $\begin{array}{l}\text { Anastasiia Barzylovych } \\
\text { Doctoral student Interregional Academy of Personnel Management, Ph.D. in } \\
\text { Medical Sciences, Director, mc KinderKlinik Kyiv, Ukraine } \\
\text { ORCID ID: https://orcid.org/0000-0002-0330-5147 } \\
\text { Email: a.barzylovych@gmail.com }\end{array}$ \\
\hline & $\begin{array}{l}\text { Alina Zabolotna } \\
\text { Ph.D. in Medical Sciences, associate professor of the department of obstetrics and } \\
\text { gynecology, Private Higher Educational Institution "Kyiv Medical University" } \\
\text { Email: a.zabolotna@kmu.edu.ua }\end{array}$ \\
\hline & $\begin{array}{l}\text { Mariia Boiko } \\
\text { Graduate student of the department, Department of Management and Business, } \\
\text { Healthcare facilities management in the context of digitalization, Institute of } \\
\text { Graduate Studies and Pre-university Education, Vasyl Stefanyk Precarpathian } \\
\text { National University } \\
\text { ORCID ID: https://orcid.org/0000-0002-6687-1082 } \\
\text { Email: boikoma@meta.ua }\end{array}$ \\
\hline (4) है ? & $\begin{array}{l}\text { Ivan Rybchych } \\
\text { Candidate of Sciences in Public Administration, Associate Professor, Department } \\
\text { of Sports Medicine, Human Health, Ivan Bobersky Lviv State University of Physical } \\
\text { Culture } \\
\text { ORCID ID: https://orcid.org/0000-0002-4578-4705 } \\
\text { Email: ribchich@gmail.com }\end{array}$ \\
\hline
\end{tabular}

